MedieKultur | Journal of media and communication research | ISSN 1901-9726

Article - Theme section

\title{
Real game worlds \\ The emotional reality of fictional worlds
}

\section{Torill Elvira Mortensen}

MedieKultur 2018, 64, 71-86

Published by SMID | Society of Media researchers In Denmark | www.smid.dk

The online version of this text can be found open access at https://tidsskrift.dk/mediekultur

\begin{abstract}
There are two ways to understand play: one is to observe it, the other is to participate in it. Since 2001, game studies has promoted participation as one of the main requirements to understand play. Some play is so performative that while it can be observed, it also must be played. Game worlds, the worlds of online, multi-user games, are delicate constructs of make-believe and technology, which act as support and arenas for immersive, theatrical and/or competitive play. This is a discussion of how far virtual ethnography can take the researcher in understanding game worlds.

To explore this, this article will address play, game worlds and transmediality, as well as discuss methods. I will look to Lisbeth Klastrup and Susana Tosca to discuss story worlds, as well as to discussions led by Celia Pearce, Tom Boellstorff and T.L. Taylor (among others) to discuss ethnography in games and virtual ethnographies.
\end{abstract}

\section{Real game worlds: The emotional reality of fictional worlds}

Studying digital games sometimes feels like studying a riddle wrapped in a mystery inside an enigma.' There are several layers of the "not real": the play situation, the fiction in which the game is set, the technology that distances it from bodily reality, the disembodiment of the players through avatars and the recreation of a world that is - no 
matter how closely it tries to be a simulation - substantially different from the one we move through every day. Peeling back a game to look for something real seems like a futile search for a core. Still, we experience an intense sense of being present in a game, a sense of what Lisbeth Klastrup calls "worldness" (2009). Worldness, according to Klastrup, can be studied "as the 'systematic study of virtual worlds as virtual worlds', including the process of examining and generalising some of the properties that define online worlds" $(2009,2003)$. More recently, authors have used this concept to discuss in-game immersion (Calleja, 2014), religion (Heidbrink, Knoll \& Wysocki, 2015, 2014), play and use (Pearce, 2009; Krzywinska, 2008) and world building (Wolf, 2014), but the term itself remains close to the definition and use by Klastrup.

The unique challenge of studying games is embedded in this sense of worldness, the feeling that games have a life and culture of their own, even when this may simply be the result of an amalgamation of overlapping modalities. This sense of a real impact on the players can be compared to larger, earlier studies that document how media have changed culture, such as Raymond Williams's (1974) and Joshua Meyrowitz's (1985) studies of how television influenced contemporary culture. Aubrey Anable points to Williams's 1958 essay "Culture Is Ordinary" as she introduces her recent book Playing with Feelings:

What if Williams had been playing Candy Crush Saga on his bus ride? The question seems irreverent, but it is one that I find worth asking when I play games on my phone in transit and watch others do the same. In these ordinary moments, what feelings are being mediated and playfully expressed through these devices, software, and images? (2018, loc. 92)

Games have a huge impact on our society. In July 2017, combined hardware/software sales in Europe, Asia and North-America were set to top $\$ 150$ billion (Merel, 2017). In 2016, 35\% of all Norwegians played a digital game on an average day (Medienorge, 2018), while two thirds of all US households had one or more persons who played three times a week (The Entertainment Software Association, 2017). However, numbers tell us very little about what it is like to play, how something several times removed from our physical world of experience can make such an impact. For that, we need to look at how players make sense of the games.

While this article will not pursue sense making in the understanding of knowledge management and information gap filling, Brenda Dervin has a valuable contribution to make to our idea of how people understand the world in which they work, and she emphasises the messiness of the experience:

Humans, Sense making assumes, live in a world of gaps: a reality that changes across time and space and is at least in part "gappy" at a given time-space; a human society filled with difference manifested in madness, culture, personality, inventiveness, tentativeness 
and capriciousness; a self that is sometimes centered, sometimes muddled, and always becoming. (Dervin, 1998, p. 36)

This messiness of the human experience is amplified by the topic of this article, by games and the playing of them. Play fits with Dervin's emphasis on knowledge management as a verb, not a noun, by being defined most readily as an experience or a process. Scott G. Eberle underlines the processual or, to use lan Bogost's (2007) term, procedural aspect of play in his article for the American Journal of Play (Eberle, 2014). The reason why this is such an important aspect of the study of games is that games are played, and play is about experience and emotion. We play to feel, and the range of emotions we experience is wide and complex. The joy of victory and the sadness or anger of loss are both important, but if it was that simple, we would most likely stop playing after the first painful losses (Juul, 2013). Instead, the player keeps playing, and so we experience the sense of progress that comes with getting better, the feeling of escape from the world that comes with being engaged or engrossed in an activity, the sense of community from playing with others, the feeling of being included and part of something bigger than oneself (Anable, 2018), and of how the play experiences become a sensory reality, if not realistic (Fasterholdt, Pichlmair \& Holmgård, 2016).

Play is not about realism and rational choices, however. Play is, by definition, something that happens in addition to the things we must do in order to get through life; as Huizinga claims, play is superfluous (Huizinga, 2000). As a superfluous activity, play is something we do when we feel like it, when the emotional reward of playing outweighs or is in conjunction with the other needs we might experience. However, this plain whimsy of gameplay makes it hard to research. The gratifications (Katz, Blumler \& Gurevitch, 1973; Bopp, Mekler \& Opwis, 2015) of play are ephemeral or highly personal, and it is very easy to misunderstand or over-interpret the actions of players. The ease with which the researcher, particularly the researcher as invested player, can over-interpret the actions of the player is a good reason to be wary of drawing sharp conclusions about player motivation, while it supports the importance of research focusing on play- and game potential, by looking at the affordances and the imaginative and fictional value produced by game content and structure.

Games are also considered to reside outside of the real through the distinction between the real and the virtual, which Boellstorff and Kozinets have underlined in their discussions of virtual worlds and net-based experiences (Boellstorff, 2012, p. 39; Kozinets, 2015, p. 69). They both underline the virtual aspect of games, with Boellstorff specifically warning about the fusing of the virtual and the actual into one domain. This adds another layer of unreality to games, creating what appears to be a great distance between the world we can observe and the world within which play happens.

Worldness challenges this idea that computer-mediated experiences are apart from the rest of reality. It ties play to reality through emotion - what is emotionally real is subjectively real. I will also further demonstrate how play and games engage deeply with 
the wider world, discussing how play is embedded in the social reality of the player, and is not separate from other human experiences. By assuming that digital games are experienced as real, we cannot ignore the technology; rather, we must see the technology as a vital part of the presence of games and play in the actual world. The worldness concept includes and expands on the mediated nature of game worlds, underlining their presence not as virtual ideas but as part of reality.

\title{
On worldness
}

Worldness explains how a game can be interpreted and experienced as a world rather than a text. Lisbeth Klastrup explored worldness in her doctoral thesis on the game EverQuest (2003), and continued to develop the term. In 2009, she presented the term as having dual aspects:

\begin{abstract}
Following, it is important to understand that the concept of worldness is applicable on two levels which continuously inform each other: we can speak of worldness on a very abstract level as a number of essential aspects applicable to all worlds and on a specific level as the defining characteristics of an individual world, reflected in the way the general properties are set into motion and transformed by the world once implemented and by its players
\end{abstract} (2009).

In her 2003 thesis, Klastrup underlines the importance of feelings but more importantly of experience for a sense of worldness. She points out that the feeling of presence in the game world does not create it; rather, it is part of how we experience an existing worldness:

Experiencing worldness is for instance also the experience of being a member of a community of users or players (social interacting) or the experience of gaming, interacting with the game world, on a more abstract level (manipulating, navigating, improving character statistics etc). (2003, p. 293)

In a 2004 work discussing worldness, Klastrup and Susana Tosca take the social interaction and room for player engagement for granted, focusing more on the structural development of transmedial worlds. However, they still underline the importance of players' activity, engagement and experience:

We have put forward the claim that transmedial cyberworlds allow the players to interact within a known and shared context, where they can be creators of their own stories and be able to expand the universe themselves by making player-built cities, objects etc. (Klastrup \& Tosca, 2004, p. 416)

One of the more recent in-depth discussions of worldness appears in Claus ToftNielsen's doctoral thesis and a more recent article on player experience $(2012,2014)$. He sees worldness as a phenomenological quality of the fantasy world, focusing on 
player experience. The present focus will be on the game world reflected through player implementation, which challenges the study of player presence, practice and communication in games. For the purposes of this article, the emphasis is on the aspects of worldness that connect to feeling, or affect, and how play moves the imagined into reality through participation and experience.

It is not just the feeling of being part of a world that turns large, contemporary games into real experiences, however. Entering a game world for the first time is easy in this era of ubiquitous connectivity and available computers. A download, an installation and some registration, and we are ready to enter into an experience we cannot have anywhere but on the computer. Whether we are travelling to Azeroth, the World of Warcraft world (Blizzard, 2004), Norrath, the EverQuest world (Sony Online Entertainment, 1999) or the myriad of planets in the Star Wars world (Bioware Austin LCC, 2011), such as Tatooine, the desert planet where Luke Skywalker grew up, or Alderaan, blown up on screen for the first time in 1977, the experience we are about to have cannot be had outside of the digital game. It is uniquely tied to the medium and the way in which games communicate connections between participants, virtual geographies and game-world laws.

\section{Digital Ethnography}

There are already tools being developed to study social worlds in digital contexts. In their work Digital ethnography, Pink, Horst, Postill, Hjort, Lewis and Tacchi (2016) discuss how ethnography needs to adjust in order to function in a society that is increasingly digitally enhanced. Digital ethnography is a very useful tool for the study of games, as we see from Boellstorff, Nardi, Pearce and Taylor's discussion of it in their work on ethnography in virtual worlds (2012). Pink et al. mention the usefulness of ethnography for the study of virtual worlds, but do not explore the methodological challenges any further than noting how discussions of virtual worlds challenge the idea of place (Pink et al., 2016, p. 128; Boellstorff, 2008). The main terms that relate to worldness and virtual worlds in the work of Pink et al. are "digital world", which refers to the world as we experience it while connected through digital devices, and "social world", which refers to the overlapping social networks that create separate but integrated experiences for humans immersed in their everyday lives. Both of these are vital for the study of virtual worlds and the worldness of games. Games and worldness exist within the digital world, as well as the social world. The experience of the social is of particular importance to worldness, as we have seen, because worldness depends on the social awareness of players. The connectedness that creates worldness (Klastrup, 2009) depends on overlapping social worlds.

However, worldness is not simply a term to underline the fact that games exist in the world. The overlapping worlds that create worldness are also an overlapping of fantastic worlds, even if this is an overlap created simply through remediation (Bolter \& Grusin, 1999) and transmediation (Klastrup \& Tosca, 2004; Ryan, 2013; Jenkins, 2007), rather than 
mythical, fictional and narrative overlap. Remediation and transmedial overlap create a new point of view with each new iteration of a narrative in a different modality, and so they create a similar sense of having an experience through several lenses to that which we have when filtering an experience through different social worlds. However, while the sense of worldness can be strengthened by or even depend on, in some cases, social connectedness within the game world, in contrast to a social world, this worldness does not rely or depend on overlapping social worlds.

And this is where the understanding of game worlds can enrich digital ethnography. Worldness offers us a tool to understand a digitally mediated world not as it is, but as it is being imagined through designed processes. Both the digital and the social worlds build on the idea that these worlds are different observation points onto a world that has not been carefully designed. Increasingly, however, the same tools that are utilised to create game worlds - transmediality, multi-modality, social connectedness in closed networks, continuous experiences of procedures and designed progress - are being utilised to create designed experiences of a mediated reality. Facebook is perhaps the most obvious example of this kind of constructed and carefully maintained world, and when we understand just how it creates a sense of worldness, we gain a better perspective on how it maintains and cocoons its users.

\section{Game materiality}

In order to understand the materiality of games, we need to understand that they have a certain type of law. To players who practice their play frequently, these laws are felt as much as known, because they are embodied, as Massumi describes it, through frequent practice and habit (2002). Game-world laws are the "natural laws" of any specific fiction, and do not need to have much of a relationship to the laws of physics of Earth. This gives the experience of digital game play a very specific materiality, because the sense of feeling is focused on a controller or a keyboard, with the action narrowed to the confines of a screen.

The relationship to this-world physics can still be felt, but not in the experience of the game world. Instead, players experience it in the tension of sitting or standing for long hours while playing, as well as in the wear and tear on the machines themselves. While the physical body is not being hit by in-game punches or frozen by spells, the player's body feels the pain of game lag, repetitive motion, or angry outbursts leading, for instance, to broken equipment (Anonymous, 2010).

This materiality is the target of a huge business in which, on top of the dedicated gaming consoles, such as Nintendo's Wii, Sony's PlayStation and Microsoft's Xbox, all of which sell in their millions, several computer brands have gaming machines developed in order to handle the particular demands of video/audio and the constant, rapid feedback necessary to mediate gameplay. These machines are often built to look futuristic and are deliberately distinguished from the mundane boxes containing hardware for regular use. 
The aesthetic of the gaming PC is a mix of science fiction, fantasy and brutalism, where blinking lights and fantastic, dramatic logos meet the need for easy access for maintenance and upgrades. While we still cannot touch the landscape the players' avatars walk through, the games are real enough to have created whole new ranges of behaviour and interaction that go far beyond the digitally restricted play, such as cosplay: dressing up as a fictional character. Nicolle Lamerichs discusses the affective aspect of game cosplay:

\begin{abstract}
My definition of an affective process charts the emotional as well as the aesthetic. First, the emphasis on emotional experiences is important because players carry a wide range of emotions towards games. I mention affection as a broader term when I speak of the cosplayer's passion for games, but I suggest that often this affection is critical. (2015, loc. 1938-1940)
\end{abstract}

One of the very interesting observations in Lamerichs's article is that the cosplay of a particular character does not have to mean that the cosplayer has actually played that character in the game; they may just feel something for the character or the world within which it exists. "Primarily, fans base themselves on the way that the character is situated in the narrative and respond to that" (Lamerichs, 2015, loc. 2024). The cosplayers' emotions bring the immaterial game world closer to physical reality through their practice. This experience is very different from the play experience itself, cosplay and game play being modalities that on the surface have very little in common, but the players are very much aware of how they create the connections. Game worldness is as much about the perceptions of players and fans as about the designed experience, as we can see in Celia Pearce's study of Uru-players, who migrated from Uru as a community in order to create a new home, retaining the features that the players defined as the vital Uru experience (Pearce, 2009).

\title{
Studying game worlds
}

Considering the size of the game industry - the US market alone was at \$12.16 billion in 2016 (Statista, 2017) - and the engagement of players with games, esports and game fan culture, it should come as no surprise that different traditions concerned with the study of culture also engage with the study of game worlds. Several studies have been written about multi-user games, both the smaller text-based multi-user games known as MOOs or MUDs (Bruckman, 1994; Bruckman \& Resnick, 1995; Bruckman, 1997; Haynes \& Holmevik, 1998; Mortensen, 2003; Parks \& Roberts, 1998; Turkle, 1994) and the MMOGs (Corneliussen \& Rettberg, 2008; Klastrup, 2003; Nardi, 2010; Pearce, 2009; Steinkuehler, 2005; Taylor, 2006) the Massively Multiplayer Online Games that are graphic representations of large imagined worlds, in which each realm or platform for simultaneous play holds tens of thousands of player accounts.

As an example of how complicated it is to gather data on these realms, let's try to figure out the size of one of the most persistent and largest online worlds, World of 
Warcraft (WoW) (Blizzard, 2004), which at its peak had 12 million subscribers. The current number of active accounts is hard to find, because Blizzard no longer publishes the data (Kollar, 2016) and it is not broken down to realm size. However, there are census programs tracking the number of players on different realms, and one of these is Realmpop.com. According to this tracking service, which claims to be based on Blizzard's data, the currently most populated US realm is home to more than 900,000 characters. Note that each player can and often does have several characters on their favourite realms, but the number is limited to 12 characters in each realm for a player account, with a maximum of 50, bringing the lowest estimate of players for the largest realms down to 75,000 (Realm Pop, 2017). Warcraftrealms, another tracking site, estimates the number of players on the largest realms to be 45,000 . The discrepancy comes from the difference in time (2015 vs 2017), as well as the different sources, as Warcraftrealms only tracks realms where enough players have agreed on being a part of the census project to collect reliable information (Warcraftrealms.com, 2015). Several realms have also been collapsed into so-called "battlegroups", in which players can play across realms. This is mainly the case for low-population realms. The WoW "instance" system allows for playing with much higher numbers of player than the population on each realm, since they match players across realms in groups and raids, but this is a much less stable unit for ethnographic study. It means that a realm can be the size of a reasonably large town, and as such offers the potential for a great variety of cultures, styles, motivations, beliefs, preferences and ethics, to mention some of the aspects of online culture. Moreover, while anonymity, lack of transparency and active resistance from players in the shape of rejection, dishonesty and trolling make it hard to study play, the variety and size make online games designed as game worlds obvious choices to study using ethnography.

This means that game scholars are used to tracking a culture in constant motion, while it has a certain stability that becomes visible through engagement in the play. The different play styles, preferences, languages used and styles of engagement reveal the kind of world that the players have chosen to construct. We can see this in several of the previous studies of game worlds.

Among the better-known studies of graphic game worlds, apart from the abovementioned work of Klastrup, we find the EverQuest (Sony Online Entertainment, 1999) studies of T.L. Taylor (2006), the Uru (Cyan Worlds, Inc., 2003) player study by Celia Pearce (2009), Tom Boellstorff's study of Second Life (Linden Research, 2003) (2008) and Bonnie Nardi's study of WoW (2010). Typical of these is the way they track the connectedness of the players and how the players find a place in the game while maintaining the game world. Equally important is how the players create the sense of worldness, of being in a space that matters, through their actions. The earliest example of this is a seminal, journalistic account by Julian Dibbell, in his description of life in the text-based game world known as LambdaMOO (Dibbell, 1993). In Dibbell's account of an instance of abuse, 
this lived experience becomes a turning point in the realisation that a game isn't just a distant, non-real playground, but a real community.

Dibbell's account demonstrates the importance of play styles and the community reaction to them in shaping the sense of being connected and sharing a common experience, the worldness. Other examples of play styles can be found in Corneliussen and Rettberg's collection of articles on WoW (2008) and Mortensen, Linderoth and Brown's collection of articles highlighting a particular play style across several different games (Mortensen, Linderoth \& Brown, 2015). It is this combination of the aesthetics of the game world, the imagined universe, the experiences and the interactions of the world that allow for the study of a culture that is as distant from the researcher as is the game. All of this is covered in Klastrup's call for the study of games not just as games or as social constructs, but as worlds (Klastrup, 2009).

When studying game worlds, the environments we enter are designed and planned, and the activities within are bound by rules, affordances and limitations. At the same time, the game and the gamers are bound by the rules, affordances and limitations of the flesh world, and more specifically by the laws of the nations and the norms of the culture in which they already exist. This makes game worlds delicate and complex constructions of layered cultures. This construction is bound together and held in place by the practice of play, which translates the structure into experience, bringing the overlapping worlds to life. Play overcomes the boundaries between the players and allows people of widely different backgrounds to interact while referencing what they all have in common: the game world within which they act. Play, by accepting or even demanding make-believe, supports the suspension of disbelief by inviting engagement by the player, rather than passive acceptance of a flawless story (Mortensen, 2015, 165). It is this layered existence of game worlds that Klastrup is reaching for as she recommends a hybrid methodology in which we need to study text, play and practice.

But is Klastrup's approach any different from the Cultural Studies method of triangulation, a mixed method approach aimed at gaining a more diverse perspective on the topic in question? Moreover, is it something other than ethnography, in which observation and participation are supplemented by the study of archives, contemporary documents and other materials relevant to the case (Saukko, 2003, 23)? Despite Klastrup's claim that there is a particular worldness that demands a new, hybrid method in order to study large online games, that claim appears to stumble over the history of qualitative methods, and when it meets modern online ethnography, there is a disconnect from Klastrup and Tosca's understanding of game worlds as entities that reach beyond simple play.

\section{Affect and engagement}

The branch of ethnography that names itself "netnography" is concerned with the technologically mediated cultures developing online. This is an ethnography that is very 
aware of the medium through which messages are communicated, and it continuously deals with this mediation. Some netnographers do so by underlining the integration of the online and the offline, such as Roser Beneito-Montagut:

I will argue in this article that everyday life takes place on the internet: there is no difference between online and offline interpersonal communication (IC). Indeed, online and offline social interactions are often intrinsically linked and we need to expand our methodological toolbox to better capture this social reality. (2011, p. 717)

However, Robert V. Kozinets's version of netnography (2015) takes a step away from the flesh world. Kozinets leans on Tom Boellstorff's (2012) claim that the symbolic universe of the designed and constructed games are separate from the flesh world, and hence can never merge, to argue in favour of a particular brand of ethnography in which "The virtual is no longer a particular piece of a wider reality better represented by 'real ethnography' or 'an ethnography of the real'. Instead it is an entire slice of a reality-in-itself" (Kozinets, 2015, p. 69).

There is no immediate conflict between Klastrup's worldness and the reality-in-itself that is Boellstorff's and Kozinets's argument. However, whereas Boellstorff's argument is based on the assumption that the virtual (online, digital) and the actual (offline, flesh world) are strictly separate (2012, p. 39), Klastrup bypasses the question and treats games as fiction. They are not attractive because they are a reality apart, but because they are fictional (2009), and when this can be considered to be an important distinction, it is because fiction is and has always been part of our reality, from lies by way of cultural identity to religion. The reality of fiction does not rest on its naturalism, but on the undeniable presence of the fictional object, the impact fiction has on our lives and, not least, the emotions fictions evoke and the ideas they inspire.

A main key to bridging the distance between the digital and the physical through the reality of fiction is affect. Affect is the step between the physical body and our feelings and emotions (Brennan, 2004, p. 5; Isbister, 2016, p. 107). We react to impulses that move us through affect, feel a surging moment of something changing in our state of mind, but this becomes emotion through being contextualised - it is controlled and directed by the framework we are currently within. The game world steers the affect towards a designed emotion.

Focused not on affect, but emotion, Anable, engaging with Raymond Williams's work, uses his term "structures of feeling" from the 1958 foreword to Film, and the 1974 work on Marxism and Literature, as a reference for discussing games. She claims that "Identifying a video game as an affective system means resisting locating properties like texture, tone, and feelings in a purely subjective experience of reception or as the exclusive property of a text, and instead locating them in the slippery and intellectually fraught place in between" (2018, loc. 166). She identifies the positioning of games as difficult because they fall between our systems for analysis, but points out the value of 
looking between reception and text, for the understanding of games and the experiences they evoke.

A designed emotion is not an unreal emotion, as we know well from rhetoric. Good rhetoric aims at controlling affect by nudging it in the direction the rhetorician desires. Thus, understanding the rhetoric of the designed worlds supports a clearer understanding of how our digital world is constantly being designed for our consumption.

However, this relationship between affect and emotion may be one reason why it can be so tricky to study game worlds, particularly if we see them as solely representing a different reality. Games demand actions based on our emotions, and sometimes, with games that are fast moving and immediate, reactions based on our affect. We react before we even know what we reacted to and end up creating situations that create a dissonance with our own actions by, for instance, using a weapon rather than trying to run away in a tight spot in a game. To justify this, we may embrace the game's rules and fictions even more strongly, and their firm grasp becomes very real - they become the wall between the actions and emotions of players. We can see the same tendency to put a set of rules and expectations between the actor and the act in Whitney Phillips's study of trolling online (2015, p. 39). This symbolic framework, as Phillips calls it, is hard to recognise while immersed in it, and while the player may not experience "bleed" in the larp (live action role play) sense, meaning a feeling of game emotions leaking into the real world (Montola, 2010), the player may still feel the reeling sense of having reacted to affect with actions that were emotionally fraught (betraying a friend, killing children, taking a dark turn) (Mortensen, 2015). This kind of potential moral dilemma is what the game space protects the player from, because it is defined as being outside of social sanction, in what Victor Turner (2009) calls a liminal space. As studies of transgressive chat cultures online have found (Coleman, 2014; Phillips, 2015; Massanari, 2015), any online space can be defined as a safe space for its users, and can become a liminal space, a space with different rules.

This is why an ethnography aiming at understanding online communication and culture needs to understand game worlds. They are not simulations of reality, but fictions of reality, both designed and co-created by the players. While this may make them a reality apart, they are still also an intrinsic part of the players' universe of experience. The bridge between these apparently separate realities is the player and the emotions and engagement of the individuals. They not only exist in both spaces, but they also define these realities and bring them together, most obviously when players want to recreate the fictional spaces in the physical world, by engaging with game worlds through, for instance, role play in the physical world (Dziobak larp studios, 2017; Maj et al., 2017) or cosplay (Fung \& Pun, 2016; Ito \& Crutcher, 2014; Lamerichs, 2015). The effects of game worlds are equally significant, however, in the way they define social relationships, create cultural references and shape identities. 


\section{Conclusion}

In order to study mediated, digital, online cultures, we need not only to take game worlds seriously, because they are increasingly important leisure homes, but also treat them as factually, emotionally and imaginatively real. In game studies, playing games is a necessity for the researchers (Aarseth, 2001, 2003, 2017), and hence we see many versions of autoethnography or participatory research, some of which are mentioned in this article. What we rarely see, however, is an ethnography of play in other contexts, although it does exist, as exemplified by Adrienne Massanari's work (2015). We know that electronic games have an impact on the players, on society and on the economy, just like other sports, as seen in studies such as T. L. Taylor's book on esports (2012) or Emma Witkowski's Ph. D. dissertation on play communities (2012). To understand the full impact of play and games, however, we need to consider the examples of Cultural Studies classics such as Raymond Williams's (1974) and Joshua Meyrowitz's (1985) studies of how television influenced culture. We also need to understand how the ludification of culture (Raessens, 2014) influences arenas beyond game worlds. One of the best ways we have to track this influence of games beyond the narrow digital arena of the game software is to follow the worldness of games as it transgresses media across platforms, materialities and practices because we, the players, carry these experiences with us, and no neat attempt at limiting them to a different reality will make their impact anything but really real.

\section{References}

Anable, A. (2018). Playing with feelings: Video games and affect. Minneapolis, MN: University of Minnesota Press.

Anonymous. (2010). Anyone else break keyboards when they rage? League of Legends community. http:// forums.na.leagueoflegends.com/board/showthread.php?t=353364\&page=2\#post4210087.

Beneito-Montagut, R. (2011). Ethnography goes online: Towards a user-centred methodology to research interpersonal communication on the internet. Qualitative Research, 11(6), (pp. 716-35). https://doi. org/10.1177/1468794111413368.

Bioware Austin LCC. (2011). Star Wars: The old republic. Electronic Arts, Inc. http://www.swtor.com/. Blizzard. (2004). World of Warcraft. Blizzard Entertainment Inc.

Boellstorff, T. (2008). Coming of age in Second Life: An anthropologist explores the virtually human. Princeton, NJ: Princeton University Press.

———. (2012). Rethinking digital anthropology. In H.A. Horst \& D. Miller (Eds.), Digital Anthropology (pp. 39-60). London: Bloomsbury.

Boellstorff, T., Nardi, B., Pearce, C., \& Taylor, T. L. (2012). Ethnography and virtual worlds : A handbook of method. Princeton, NJ.: Princeton University Press.

Bogost, I. (2007). Persuasive games: The expressive power of videogames. Cambridge, MA: MIT Press.

Bolter, J.D., \& Grusin, R. (1999). Remediation: Understanding new media. Cambridge, MA: MIT Press. 
Bopp, J., Mekler, E. \& Opwis, K. (2015). "It was sad but still good": Gratifications of emotionally moving game experiences. CHI'15 extended abstracts. Seoul, Republic of Korea. (pp. 1193-1198). https://dl.acm. org/citation.cfm?id=2702613.2732852.

Brennan, T. (2004). The transmission of affect. Ithaca, NY: Cornell University Press.

Bruckman, A. (1994). Programming for fun: MUDs as a context for collaborative learning. https://eric. ed.gov/?id=ED396675.

Bruckman, A., \& Resnick, M. (1995). The MediaMOO project. Convergence: The International Journal of Research into New Media Technologies 1(1), (pp. 94-109). https://doi.org/10.1177/135485659500100110.

Bruckman, A.S. (1997). MOOSE crossing: Construction, community and learning in a networked virtual world for kids. Ph.D. thesis, Massachusetts Institute of Technology, Program in Media Arts \& Sciences. http://dspace.mit.edu/handle/1721.1/33821.

Calleja, G. (2014). Immersion in virtual worlds. In M. Grimshaw (Ed.), The Oxford handbook of virtuality (pp. 254-68). Oxford and New York, NY: Oxford University Press.

Coleman, G. (2014). Hacker, hoaxer, whistleblower, spy: The many faces of Anonymous. London: Verso.

Corneliussen, H., \& Walker Rettberg, J. (2008). Digital culture, play, and identity: A World of Warcraft reader. MIT Press.

Cyan Worlds, Inc. (2003). Uru: Ages beyond Myst. Ubisoft.

Dervin, B. (1998). Sense-making theory and practice: An overview of user interests in knowledge seeking and use. Journal of Knowledge Management 2(2), (pp. 36-46). https://doi. org/10.1108/13673279810249369.

Dibbell, J. (1993). A rape in cyberspace. The Village Voice. http://www.juliandibbell.com/texts/bungle_ vv.html.

Dziobak larp studios. (2017). College of Wizardry. https://www.cowlarp.com/.

Eberle, S.G. (2014). The elements of play: Toward a philosophy and a definition of play. American Journal of Play 6(2), (pp. 214-33.) https://files.eric.ed.gov/fulltext/E)1023799.pdf.

Fasterholdt, M., Pichlmair, M., \& Holmgård, C. (2016). You say jump, I say how high? Operationalising the game feel of jumping. In Proceedings of the first international joint conference of DiGRA and FDG. (pp. 1-16) https://library.med.utah.edu/e-channel/wp-content/uploads/2017/02/paper_248.pdf.

Fung, A.Y.H., \& Pun, B.L.F. (2016). From pioneering amateur to tame co-operator: Tamed desires and untamed resistance in the cosplay scene in China. In A. Pulos \& S. Austin Lee (eds.), Transnational contexts of culture, gender, class, and colonialism in play: Video games in East Asia (pp. 81-96). Basingstoke, UK: Palgrave Macmillan.

Haynes, C., \& Holmevik, J.R. (1998). High wired: On the design, use, and theory of educational MOOs. Ann Arbor, MI: University of Michigan Press.

Heidbrink, S., Knoll, T., \& Wysocki, J. (2014). Theorizing religion in digital games. perspectives and approaches. Heidelberg Journal of Religions on the Internet 5. (pp. 5-50). https://doi.org/10.11588/ REL.2014.0.12156.

———. (2015). "Venturing into the unknown"(?): Method(olog)ical reflections on religion and digital games, gamers and gaming. Heidelberg Journal of Religions on the Internet 7. (pp. 61-84). https://doi. org/10.11588/REL.2015.0.18508.

Huizinga, J. (2000). Homo ludens: A study of the play element in culture. London: Routledge. Isbister, K. (2016). How games move us: Emotion by design. Cambridge, MA: The MIT Press.

Ito, K., \& Crutcher, P.A. (2014). Popular mass entertainment in Japan: Manga, pachinko, and cosplay. Society 51(1), (pp. 44-48). https://doi.org/10.1007/s12115-013-9737-y.

Jenkins, H. (2007). Transmedia storytelling 101. Confessions of an aca-fan. March 21, 2007. http://henryjenkins.org/blog/2007/03/transmedia_storytelling_101.html. 
Juul, J. (2013). The art of failure: An essay on the pain of playing video games. Cambridge, MA: MIT Press. Katz, E., Blumler, J.G., \& Gurevitch, M. (1973). Uses and gratifications research. Public Opinion Quarterly 37(4), 509. https://doi.org/10.1086/268109.

Klastrup, L. (2003). Towards a poetics of virtual worlds: Multi-user textuality and the emergence of story. Copenhagen: IT University of Copenhagen.

- - . (2009). The worldness of EverQuest: Exploring a 21st century fiction. Game Studies: The International Journal of Computer Game Research 9(1). http://gamestudies.org/0901/articles/klastrup.

Klastrup, L., \& Tosca, S. (2004). Transmedial worlds: Rethinking cyberworld design. In 2004 international conference on cyberworlds (pp. 409-16). Tokyo: IEEE. https://doi.org/10.1109/CW.2004.67.

Kozinets, R.V. (2015). Netnography: Redefined. London: Sage.

Krzywinska, T. (2008). World creation and lore: World of Warcraft as rich text. In H.G. Corneliussen \& J. Walker Rettberg (Eds.), Digital culture, play, and identity: A World of Warcraft reader (pp. 123-142). Cambridge, MA: MIT Press.

Lamerichs, N. (2015). Express yourself: An affective analysis of game cosplayers. In J. Enevold \& E. MacCallum-Stewart (Eds.), Game love: Essays on play and affection. Kindle edition. Jefferson, NC: Macfarland $\&$ Company, Inc.

Linden Research, Inc. (2003). Second Life. http://secondlife.com/.

Maj, K., Zioło, B., Trojanowska, D.K., Sokólska, A., \& Starosta, M. (2017). Witcher school. http://witcherschool.com/en/organizers/.

Massanari, A.L. (2015). Participatory culture, community, and play. New York, NY: Peter Lang US.

Massumi, B. (2002). Parables for the virtual: Movement, affect, sensation. Durham, NC: Duke University Press.

Medienorge. (2018). Bruk av elektroniske spill en gjennomsnittsdag - Medienorge - Fakta om Norske massemedier - statistikkmeny. Nordicom. http://medienorge.uib.no/statistikk/medium/ikt/411.

Merel, T. (2017). Games software/hardware revenue to top \$150 billion in 2017. VentureBeat, July 13. https://venturebeat.com/2017/07/13/games-revenue-will-top-150-billion-in-2017-and-keep-growing/.

Meyrowitz, J. (1985). No sense of place: The impact of electronic media on social behavior. New York, NY: Oxford University Press.

Montola, M. (2010). The positive negative experience in extreme role-playing. In Nordic DiGRA 2010 (pp. 1-8 ). http://www.digra.org/wp-content/uploads/digital-library/10343.56524.pdf.

Mortensen, T.E. (2003). Pleasures of the player: Flow and control in online games. Ph.D. thesis, University of Bergen.

_- - (2015). Keeping the balance: Morals at the dark side. In T. E. Mortensen, J. Linderoth, \& A.M.L. Brown (Eds.), The Dark Side of Game Play: Controversial Issues in Playful Environments (pp. 155-70). London: Routledge. https://doi.org/10.4324/9781315738680.

Mortensen, T.E., Linderoth, J., \& Brown, A.M.L. (2015). The dark side of game play: Controversial issues in playful environments. London: Routledge.

Nardi, B.A. (2010). My life as a night elf priest: An anthropological account of World of Warcraft. Ann Arbor: University of Michigan Press.

Parks, M.R., \& Roberts, L.D. (1998). "Making moosic": The development of personal relationships on line and a comparison to their off-line counterparts. Journal of Social and Personal Relationships 15(4), (pp. 517-37). https://doi.org/10.1177/0265407598154005.

Pearce, C. (2009). Communities of play: Emergent cultures in multiplayer games and virtual worlds. Cambridge, MA: MIT Press.

Phillips, W. (2015). This is why we can't have nice things: Mapping the relationship between online trolling and mainstream culture. Cambridge, MA: MIT Press. 
Pink, S., Horst, H.A., Postill, J., Hjorth, L., Lewis, T., \& Tacchi, J. (2016). Digital ethnography: Principles and practice. Kindle edn. London: Sage.

Raessens, J. (2014). The ludification of culture. In M. Fuchs, S. Fizek, P. Ruffino, \& N. Schrape (Eds.), Rethinking gamification. Lüneburg: Meson Press. http://projects.digital-cultures.net/meson-press/ files/2014/06/9783957960016-rethinking-gamification.pdf.

Realm Pop. (2017). Realm pop. https://realmpop.com/.

Ryan, M-L. (2013). Transmedial storytelling and transfictionality. Poetics Today 34(3). (pp. 361-388). https:// doi.org/10.1215/03335372-2325250.

Saukko, P. (2003). Doing research in cultural studies: An introduction to classical and new methodological approaches. London: Sage.

Sony Online Entertainment. (1999). EverQuest.

Statista. (2017). U.S. video game industry annual revenue by segment 2016. https://www.statista.com/statistics/249996/annual-revenue-of-the-us-video-game-industry-by-segment/.

Steinkuehler, C.A. (2005). Cognition and learning in massively multiplayer online games: A critical approach. Ph.D. thesis, University of Wisconsin-Madison. http://website.education.wisc.edu/steinkuehler/thesis.html.

Taylor, T.L. (2006). Play between worlds: Exploring online game culture. Cambridge, MA: MIT Press.

The Entertainment Software Association. (2017). Essential facts about the computer and video game industry: 2017 sales, demographic and usage data. http://www.theesa.com/wp-content/ uploads/2017/09/EF2017_Design_FinalDigital.pdf.

Toft-Nielsen, C. (2012). Gamingpraksis: En vidvinkeloptik på computerspil, køn, genre og hverdagsliv - forskning - Aarhus Universitet. http://pure.au.dk/portal/da/persons/claus-toftnielsen(6ddec7935dc7-4541-8c34-ba6881a8c1b8)/publications/gamingpraksis-en-vidvinkeloptik-paa-computerspil-koen-genre-og-hverdagsliv(2f714d4a-f91e-465d-b0bf-dfaed0d37304).html.

- - . (2014). Worlds at play: Space and player experience in fantasy computer games. Nordicom Review 35(Special Issue), (pp. 237-49).

Turkle, S. (1994). Constructions and reconstructions of self in virtual reality: Playing in the MUDs. Mind, Culture, and Activity 1(3), (pp. 158-67). https://doi.org/10.1080/10749039409524667.

Turner, V. (2009). Liminal to liminoid, in play, flow, and ritual: An essay in comparative symbology. Rice University Studies, 60(3), (pp. 53-92). https://scholarship.rice.edu/handle/1911/63159.

Warcraftrealms.com. (2015). WoW server stats - EU Realms. http://www.warcraftrealms.com/eu_realmstats.php.

Williams, R. (1974). Television: Technology and cultural form. London: Fontana/Collins.

Wolf, M.J.P. (2014). Building imaginary worlds: The theory and history of subcreation. London: Routledge.

Aarseth, E. (2001). Editorial, game studies 0101. Gamestudies.org 1(1). http://www.gamestudies.org/0101/ editorial.html.

-_- (2003). Playing research: Methodological approaches to game analysis. In Proceedings of Melbourne Digital Arts \& Culture Conference.

- - (2017). Just games. Game Studies: The International Journal of Computer Game Research, 17(1). http://gamestudies.org/1701/articles/justgames.

\section{Endnotes}

1 Winston Churchill on Russia in 1939. 
Article: Real game worlds

Torill Elvira Mortensen IT University of Copenhagen Department of Digital design Center for Games Research Culture and Technology Toel@itu.dk 